\title{
The Role of Soya Oil Ester in Water-Based PCM for Low Temperature Cool Energy Storage
}

\author{
I. M. Rasta, ${ }^{1}$ I. N. G. Wardana, ${ }^{2}$ N. Hamidi, ${ }^{2}$ and M. N. Sasongko ${ }^{2}$ \\ ${ }^{1}$ Mechanical Engineering, Bali State Polytechnic, Bali 80361, Indonesia \\ ${ }^{2}$ Department of Mechanical Engineering, Brawijaya University, Malang 65151, Indonesia \\ Correspondence should be addressed to I. M. Rasta; maderasta@pnb.ac.id
}

Received 5 June 2016; Revised 27 July 2016; Accepted 2 August 2016

Academic Editor: M. A. Rosen

Copyright (c) 2016 I. M. Rasta et al. This is an open access article distributed under the Creative Commons Attribution License, which permits unrestricted use, distribution, and reproduction in any medium, provided the original work is properly cited.

\begin{abstract}
This study focuses on the preparation of the water-based phase change material (PCM) with very small soya oil solution for low temperature latent heat thermal energy storage (LHTES). Soya oil ester is soluble very well in water and acts as nucleating agent for a novel solid-liquid PCM candidate that is suitable for low temperature cool storage in the range between $-9^{\circ} \mathrm{C}$ and $-6^{\circ} \mathrm{C}$. Thermal energy storage properties of the water with very small soya oil ester solution were measured by T-history method. The experimental results show that very small amount of soya oil ester in water can lower the freezing point and trigger ice nucleation for elimination of the supercooling degree. The phase transition temperatures of the water-based PCMs with soya oil as nucleate agent were lower than those of individual water. The thermal properties make it potential PCM for LHTES systems used in low temperature cool energy storage applications.
\end{abstract}

\section{Introduction}

There are three ways to store energy, that is, thermochemical energy storage, sensible storage, and latent heat storage [1]. Latent heat storage (LHS) has the ability to save energy per mass unit in a large quantity and release it on constant temperature and compensate the imbalanced energy between the heat produced and the heat consumed [2-4]. LHS is based on the heat absorption or release when the stored material undergoes change of phase from solid to liquid or vice versa $[5,6]$.

In general, PCM is classified into organic compounds, inorganic compounds, and their binary mixtures that melt and solidify at a range of temperatures [7]. Among some investigation, the most familiar PCM is water. Water is mainly used as the PCM for cold storage because it has very good thermal characteristics, such as stability, reliability, being inexpensive, high specific heat, high density, high latent heat capacity of $334 \mathrm{~kJ} / \mathrm{kg}$, and safety $[8,9]$. This technology has been used and is available commercially. Yet, its frozen temperature is $0^{\circ} \mathrm{C}$ and its degree of supercooling is high $[10,11]$. Because of the supercooling, the temperature needs to be lowered far below the temperature of changing phase to start the crystallization and release the latent heat stored in PCMs. If the formation of ice nucleation does not occur and the temperature is unreachable, PCM will never be frozen at all and, thus, only save the sensible heat [12-14]. When the medium for the thermal transfer is not in sufficiently low temperature to cope with the supercooling effect, it can cause some problem on storage filling [15]. The high degree of supercooling during the freezing process causes the temperature for evaporation in freezer to be lower; as a result, the efficiency of the refrigeration decreases. Therefore, in the practical application of PCMs, the degree of supercooling becomes an important parameter and it has a big effect on the performance of the system [16-18].

So far, to lower the freezing point of water for the low temperature PCM, hydrated salt is used. Hydrated salt can initiate the water crystallization during the freezing process and tends to change the phase above $0^{\circ} \mathrm{C}\left(32^{\circ} \mathrm{F}\right)$. The eutectics blend of salt solution within water has changing phase of temperature below $0^{\circ} \mathrm{C}\left(32^{\circ} \mathrm{F}\right)$ [19]. Yet, it has several weaknesses, for instance, incongruent melting, different density, phase segregation, and sedimentation within the container. 
TABLE 1: Chemical composition of commercial soya oil ester.

\begin{tabular}{lcc}
\hline Component name & Formula & Area (\%) \\
\hline Benzene, 1-(1,5-dimethyl-4-hexenyl) & $\mathrm{C}_{15} \mathrm{H}_{22}$ & 16.04 \\
Zingiberene, 1,3-cyclohexadiene, 5-(1,5-dimethyl-4-hexenyl) & $\mathrm{C}_{15} \mathrm{H}_{24}$ & 6.85 \\
Cyclohexene, 1-methyl-4-(5-methyl-1-methylene-4-hexenyl) & $\mathrm{C}_{15} \mathrm{H}_{24}$ & 11.32 \\
Dodecanoic acid, methyl ester (CAS) methyl laurate & $\mathrm{C}_{13} \mathrm{H}_{26} \mathrm{O}_{2}$ & 5.30 \\
4-Octenoic acid, methyl ester & $\mathrm{C}_{9} \mathrm{H}_{16} \mathrm{O}_{2}$ & $\mathrm{C}_{15} \mathrm{H}_{24}$ \\
Beta-sesquiphellandrene & $\mathrm{C}_{22} \mathrm{H}_{10} \mathrm{O}_{6}$ \\
6,7-Dihydroxy-5,8,13,14-pentaphenetetrone & $\mathrm{C}_{17} \mathrm{H}_{34} \mathrm{O}_{2}$ \\
Hexadecanoic acid, methyl ester & $\mathrm{C}_{18} \mathrm{H}_{34} \mathrm{O}_{4}$ \\
Dodecanoic acid, (2,2-dimethyl-1,3-dioxolan-4-yl)methyl ester & $\mathrm{C}_{22} \mathrm{H}_{42} \mathrm{O}_{4}$ \\
Hexadecanoic acid, (2,2-dimethyl-1,3-dioxolan-4-yl)methyl ester & $\mathrm{C}_{23} \mathrm{H}_{44} \mathrm{O}_{4}$ \\
2-Heptadecanone, 1-(2,2-dimethyl-1,3-dioxolan-4-yl)methoxy & $\mathrm{C}_{19} \mathrm{H}_{36} \mathrm{O}_{2}$ \\
10-Octadecenoic acid, methyl ester & $\mathrm{C}_{20} \mathrm{H}_{40} \mathrm{O}_{2}$ \\
Nonadecanoic acid, methyl ester & \\
\hline
\end{tabular}

It is a serious problem in practical application. Another weakness of hydrated salt is the fact that the capability of forming the nucleation is not really good which results in significant supercooling. Besides, it causes corrosion for metal component of energy storage [20, 21].

In the future, the trend of technology development for PCM is based on bio [22]. In this research, commercial soya oil ester is chosen as the agent of nucleation. Soya oil ester contains many unsaturated fatty acids. The more the unsaturated fatty acids are, the lower the melting point is, because the van der Waals attractive force becomes less effective. Moreover, among all organic and mixed PCMs fatty acids, fatty acid ester and eutectic blend also have many advantages, including the definite melting temperature, high thermal capacity, congruent melting, no refrigeration during the phase transition, low vapor pressure, being nonpoisonous, being noncorrosive, good thermal and chemical stability material, low expense, being inflammable, a small change of volume, and continual stock availability [23-27].

Though Jeong et al. [28] have done experimental study to improve thermal conductivity of bio-based PCMs for increasing thermal efficiency, the latent heat capacity of biobased PCMs which is $149.2 \mathrm{~kJ} / \mathrm{kg}$ is half of that of water. Therefore, this paper provides data of water-based PCM which has very high latent heat capacity with a little solution of soya oil ester so that either the pressure or volume is almost unchanged. Besides, the thermal characteristic is expected to not be far different with water and formulation of PCM.

The main problem of the phase change thermal energy storage (TES) technology is to develop effective PCMs to save energy [29]. Suitable temperature for changing phase and a high melting enthalpy are two essential requirements for a PCM [30]. Therefore, the main objective of this study is to develop low-expense PCMs for TES application. For this purpose, commercial soya oil ester is applied as nucleating agent in water-based PCMs and their thermal properties are measured through the T-history method. The PCMs in the present work can be applied for low temperature cool energy storage.

\section{Materials and Methods}

2.1. Materials. The material used in this study is natural ester oils extracted from soya bean. These vegetable oils are used without further purification. Soya oil ester is chosen because it contains polyunsaturated fatty acids (PUFA) which cause its freezing and melting temperature to become relatively low. Chemical composition of soya oil ester was tested with Gas Chromatography Mass Spectrometry (GCMS) as in Table 1 .

Ester is derived from acids in which one hydroxyl $(-\mathrm{OH})$ group is replaced by one alkyl (-O) group [22]. In the water solvent, certain acid molecules having -OH cluster part of its molecules are ionized by releasing hydrogen $(\mathrm{H})$ atom to generate $\mathrm{H}^{+}$ion. The polarity of the soya oil ester makes it soluble in water.

The test result in Table 1 shows that commercial soya oil ester is composed mainly of methyl esters of $53.89 \%$. The soya oil ester also contains benzene (16.4\%), 1,3-cyclohexadiene (6.85\%), beta-sesquiphellandrene (11.55\%), and others of about $11.68 \%$.

\subsection{Preparation of Vegetable Oil in Water Eutectic Mixture as} $P C M$. In this research, to reduce changing phase temperature of pure water, small amount of soya oil ester was applied as a dispersed phase in tap water as a continuous phase. The water-based PCM was prepared at different concentrations (in \% volume) of soya oil ester in the water, namely, $12.5 \%$, $15 \%$, and $17.5 \%$. The $10 \mathrm{~mL}$ PCM sample was inserted in a glass tube which was then immersed in $-20^{\circ} \mathrm{C}$ water bath. The typical composition of tap water is tabulated in Table 2 along with that of local mineral water for comparison. The impurity in tap water in general is larger than that of mineral water.

\subsection{Measurement Techniques of Supercooling and Freezing} Temperature. Water is the basic material of PCM observed. The test for PCM with high level of supercooling needs a somewhat large volume of sample. Therefore, in this research, 
TABLE 2: Typical composition of local mineral and tap water.

\begin{tabular}{|c|c|c|c|c|c|}
\hline \multirow{2}{*}{ Number } & \multirow{2}{*}{ Parameter } & \multirow{2}{*}{ Unit } & \multicolumn{2}{|c|}{ Test results } & \multirow{2}{*}{ Methods of analysis } \\
\hline & & & Mineral water & Tap water & \\
\hline & & & Physical & & \\
\hline 1 & Odour & - & Odourless & Odourless & Organoleptic \\
\hline 2 & Taste & - & Tasteless & Tasteless & Organoleptic \\
\hline 3 & Colour & Scala TCU & 0 & $<3$ & Calorimetric \\
\hline 4 & Turbinity & Scala NTU & 0.01 & 0.26 & Turbidimetric \\
\hline 5 & Total dissolved solid & $\mathrm{mg} / \mathrm{L}$ & 163 & 306 & Conductometric \\
\hline \multirow[t]{2}{*}{6} & Temperature & ${ }^{\circ} \mathrm{C}$ & $27^{\circ} \mathrm{C}$ & $27^{\circ} \mathrm{C}$ & Thermometer \\
\hline & \multicolumn{5}{|c|}{ Chemical } \\
\hline 1 & Mercury (Hg) & $\mathrm{mg} / \mathrm{L}$ & 0.00 & $<0.01$ & AAS/spectrophotometric \\
\hline 2 & Aluminium (Al) & $\mathrm{mg} / \mathrm{L}$ & $<0.01$ & - & Alizarin \\
\hline 3 & Arsenic (As) & $\mathrm{mg} / \mathrm{L}$ & 0.00 & $<0.01$ & AAS \\
\hline 4 & Iron $(\mathrm{Fe})$ & $\mathrm{mg} / \mathrm{L}$ & $\leq 0.003$ & 0.045 & AAS \\
\hline 5 & Fluoride (F) & $\mathrm{mg} / \mathrm{L}$ & $\leq 0.01$ & 0.327 & Spectrophotometric \\
\hline 6 & Cadmium $(\mathrm{Cd})$ & $\mathrm{mg} / \mathrm{L}$ & $<0.002$ & $<0.003$ & AAS \\
\hline 7 & Total hardness $\left(\mathrm{CaCO}_{3}\right)$ & $\mathrm{mg} / \mathrm{L}$ & 97 & 261.516 & Titrimetric \\
\hline 8 & Chloride $\left(\mathrm{Cl}^{-}\right)$ & $\mathrm{mg} / \mathrm{L}$ & 10.23 & 26.89 & Argentometric \\
\hline 9 & Chlorine $\left(\mathrm{Cl}_{2}\right)$ & $\mathrm{mg} / \mathrm{L}$ & 0.01 & 1.8 & Titrimetric \\
\hline 10 & Ammonium $\left(\mathrm{NH}_{4}\right)$ & $\mathrm{mg} / \mathrm{L}$ & $<0.008$ & 0.012 & Spectrophotometric (Nessler) \\
\hline 11 & Chromium Val-6 $\left(\mathrm{Cr}^{6+}\right)$ & $\mathrm{mg} / \mathrm{L}$ & $<0.008$ & 0.008 & AAS \\
\hline 12 & Manganese (Mn) & $\mathrm{mg} / \mathrm{L}$ & 0.00 & $<0.001$ & Calorimetric \\
\hline 13 & Nitrate $\left(\mathrm{NO}_{3}\right)$ & $\mathrm{mg} / \mathrm{L}$ & 0.02 & 0.094 & Spectrophotometric (brucine) \\
\hline 14 & Nitrite $\left(\mathrm{NO}_{2}\right)$ & $\mathrm{mg} / \mathrm{L}$ & $<0.004$ & 0.071 & Spectrophotometric (NED) \\
\hline 15 & $\mathrm{pH}$ & $\mathrm{mg} / \mathrm{L}$ & 7 & 6.9 & pH-meter \\
\hline 16 & Selenium & $\mathrm{mg} / \mathrm{L}$ & 0.00 & $<0.006$ & AAS \\
\hline 17 & Zinc (Zn) & $\mathrm{mg} / \mathrm{L}$ & $\leq 0.01$ & 0.1037 & AAS \\
\hline 18 & Cyanide (Cn) & $\mathrm{mg} / \mathrm{L}$ & $<0.001$ & $<0.002$ & Calorimetric \\
\hline 19 & Sulfate $\left(\mathrm{SO}_{4}\right)$ & $\mathrm{mg} / \mathrm{L}$ & $\leq 2.93$ & 4.884 & Turbidimetric \\
\hline 20 & Copper $(\mathrm{Cu})$ & $\mathrm{mg} / \mathrm{L}$ & $\leq 0.004$ & $<0.0075$ & AAS \\
\hline \multirow[t]{2}{*}{21} & Timbal $(\mathrm{Pb})$ & $\mathrm{mg} / \mathrm{L}$ & 0.00 & $<0.0153$ & AAS \\
\hline & \multicolumn{5}{|c|}{ Microbiological } \\
\hline 1 & Escherichia coli & $\mathrm{AMP} / 100 \mathrm{~mL}$ & 0 & 0 & SNI 06-4158-1996 (MPN) \\
\hline 2 & Total coliform & $\mathrm{AMP} / 100 \mathrm{~mL}$ & 0 & $<0.18$ & SNI 06-4158-1996 (MPN) \\
\hline
\end{tabular}

thermal properties of the samples are measured by using a $\mathrm{T}$ history method.

Schematic diagram of the supercooling measurement system is shown in Figure 1. It can be seen that the measurement system comprises a thermostatic bath and a data logging system. The process of ice nucleation during the phase change was recorded visually by using CCD video camera, as shown in Figure 2.

Figure 1 shows that PCM was contained in glass tubes and immersed into the cooling medium of the water bath with $40 \%$ (by volume) polypropylene glycol. The cooling medium was circulated by a pump through evaporator of a refrigeration system, where it was cooled. Temperature of cooling medium can reach as low as $-25^{\circ} \mathrm{C}$. For the test, however, temperature of the cooling medium was maintained stable at temperature of $-20^{\circ} \mathrm{C}$ by using digital thermostat of $\pm 0.2^{\circ} \mathrm{C}$ accuracy.
The data logging system shown in Figure 1 was equipped with data acquisition modules and a computer for recording or display system. The data acquisition modules utilized a Datascan 7000 series from MSL (Measurement System Ltd.) including a Datascan measurement processor 7320 and expansion modules 7020. Each Datascan module contains 16 differential input channels, individually configurable for voltage and thermocouple measurements. T-type thermocouples were used to measure the low cooling temperatures of the PCM candidates.

The thermocouples have a temperature measurement range from $-250^{\circ} \mathrm{C}$ to $350^{\circ} \mathrm{C}$ with uncertainty of $\pm 0.5^{\circ} \mathrm{C}$. The thermocouples were calibrated using a calibration bath with precision thermometer of uncertainty of $\pm 0.04^{\circ} \mathrm{C}$. The temperature range of calibration was from $-25^{\circ} \mathrm{C}$ to $50^{\circ} \mathrm{C}$.

The phenomenon of ice nucleation in supercooled liquid water was recorded using CCD video camera, as shown in 


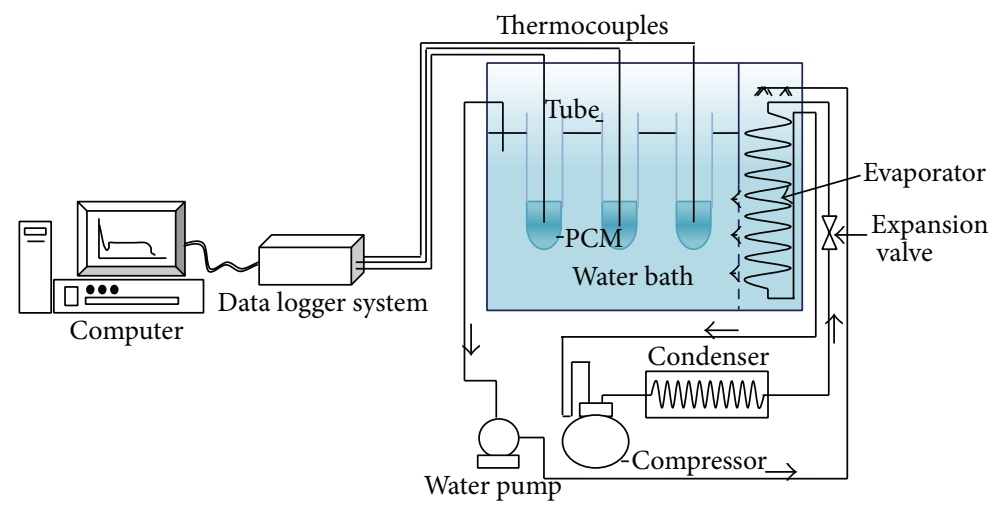

FIGURE 1: Schematic diagram of experimental test equipment using T-history method.

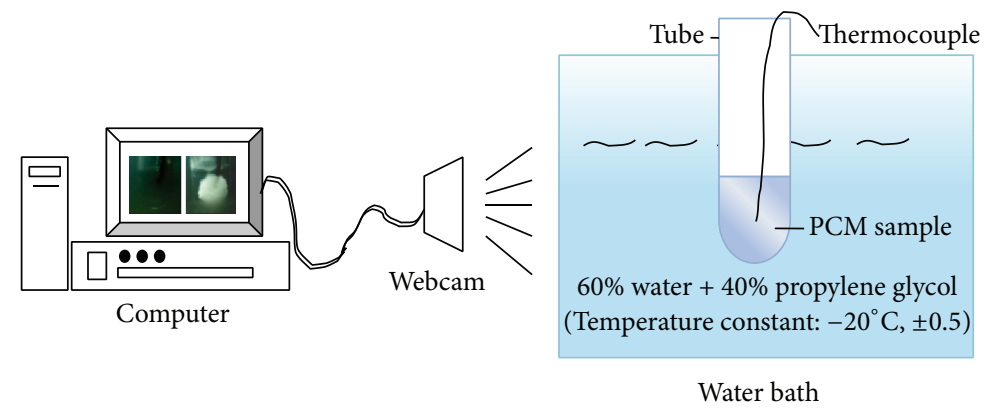

FIGURE 2: T-history method equipped with webcam.

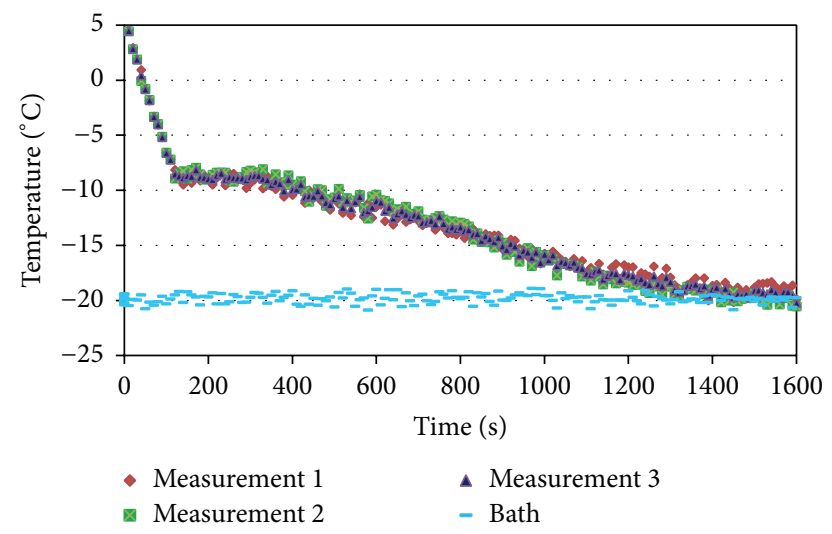

FIGURE 3: Data consistency for cooling process of $17.5 \%$ soya oil ester solutions in tap water at bath temperature of $-20^{\circ} \mathrm{C}$.

Figure 2. This observation is aimed at studying the freezing process based on the fact that ice nucleation is exothermic process and thermal fusion release of water changing phase from liquid to solid. The technique of visualization enables the researchers to determine the early location for ice nucleation and monitor the spread on its area. Also, it enables them to decide the extrinsic and intrinsic role of nucleating agent in the process of ice spreading in the freezing process. The temperature history measurement was repeated three times as shown in Figure 3 for $17.5 \%$ soya oil. The consistency of the data is $99.5 \%$. This research gives a

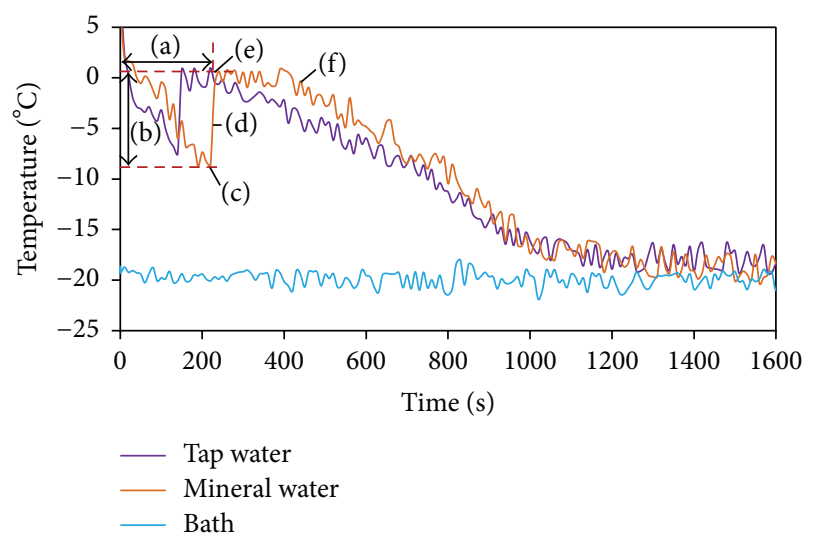

FIgURE 4: Temperature in the center of samples at bath temperature of $-20^{\circ} \mathrm{C}$. (a) Ice nucleation delay. (b) Supercooling degree. (c) Ice nuclei. (d) Growth ice crystal. (e) Initial formation of solid ice layer. (f) Complete formation of solid ice layer.

portrayal of some factors having important role to accurately predict the freezing pattern.

\section{Results and Discussion}

3.1. Supercooling and Freezing Temperature Analysis. Figure 4 shows that tap and mineral water were supercooled to reach $-7.5^{\circ} \mathrm{C}$ and $-8.5^{\circ} \mathrm{C}$, respectively. Crystallization occurs after the temperature of the liquid is far below the freezing 
temperature. Water is still fluid until it becomes below the freezing temperature and, eventually, the water molecule must form the ice crystal because of the low temperature. The freezing started to happen on the surface of the liquid first so that there is heat trapped within the solution. When the heat has been spread evenly to all substance, the temperature increases until it meets the freezing point.

The characteristic of supercooling degree between tap water and mineral water is different. Mineral water has higher supercooling degree than tap water. Water can be supercooled, since the crystal nucleation and growth may take a longer time. The ice nucleation delay between tap water and mineral water is different, since the purity or the content of particle of tap and mineral water is different. Ice nucleation delay for mineral water is longer because there is no/fewer content of particle that is able to initiate the nucleation.

The ice crystallization of supercooled water is generally started with the process called nucleation formation. Water that eventually forms the ice crystal because of the low temperature is called homogenous nucleation. Formation of ice crystal which is caused by the combination of water molecules is called homogeneous nucleation. It occurs in a condition where the substance is freed from particles (agent nucleation) that generally play a role as nuclei when the freezing process happens. Meanwhile, heterogeneous nucleation occurs when the water molecules are united with the nucleation agent or the particles of dissolved substance [3133]. Homogenous nucleation usually occurs at temperature which is lower than heterogeneous nucleation.

Figure 5 shows that PCM with different concentration of soya oil ester can quickly trigger the formation of ice nucleation at high temperature which almost meets the freezing point of the PCM. The additions of $12.5 \%, 15 \%$, and $17.5 \%$ of soya oil ester in the PCM can decrease tap water freezing point to $-6^{\circ} \mathrm{C},-8^{\circ} \mathrm{C}$, and $-9.5^{\circ} \mathrm{C}$, respectively. They can also reduce supercooling degree to $1.0 \mathrm{~K}, 0.6 \mathrm{~K}$, and $0.4 \mathrm{~K}$, respectively. Even at just 1 or $2^{\circ} \mathrm{C}$ of supercooling [34], the molecule of water that is fused with the nucleation formed in PCM increases the rate of crystal growth until the condition of the solution is stable.

The stable condition of the PCM is gained when there is no more crystal formation. The addition of soya oil ester as dissolved particle substance into tap water as fusion results in some ion which contributes to the intermolecular energy between the fusing particle and fused substance. During the refrigeration process, the attractive energy between the fusing particle and fused substance releases more energy/heat so that the freezing point is decreased. Therefore, this soya oil ester solution reduces the supercooling because of the quicker nucleation formation and the lower freezing point drops down. The role of soya oil ester is to reduce or even omit the degree of supercooling and decrease the freezing point at certain limit matched with the concentration of the solution.

\subsection{The Role of Corn Oil Ester in the Ice Nucleations Analysis.} Figure 6 shows the freezing process in the system of latent heat thermal energy storage (LHTESS). The addition of $12.5 \%$, $15 \%$, and $17.5 \%$ of soya oil ester in tap water can cause the
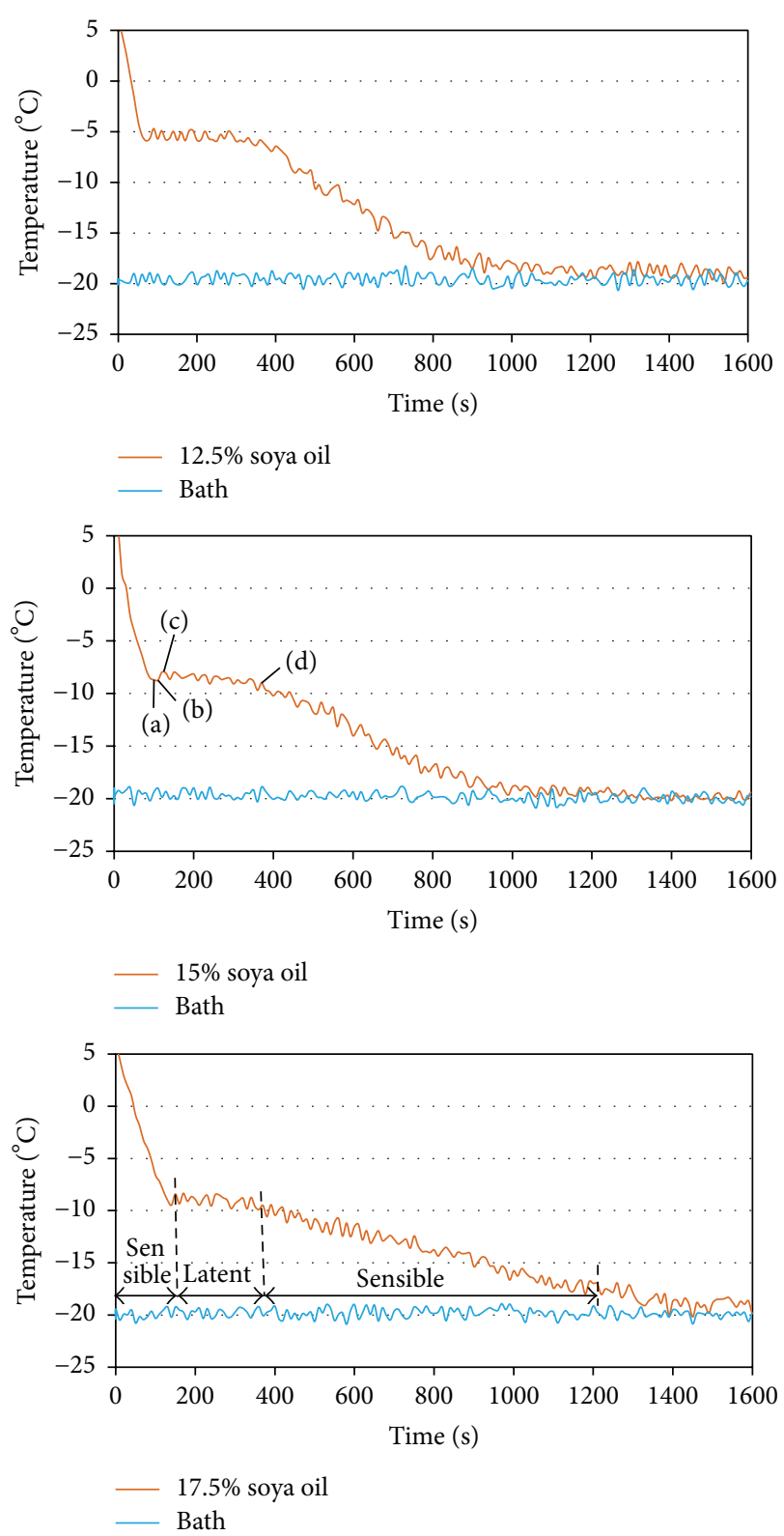

FIGURE 5: Cooling process of $12.5 \%, 15 \%$, and $17.5 \%$ of soya oil ester solutions in tap water at bath temperature of $-20^{\circ} \mathrm{C}$. (a) Ice nuclei. (b) Growth ice crystal. (c) Initial formation of solid ice layer. (d) Complete formation of solid ice layer.

molecule of water to freeze faster than the pure tap water. Crystallite is created spontaneously as the result of incessant jiggling of the whole molecule within the liquid because of the thermal fluctuation.

Crystals are formed in PCM, growing out and expanding in the surface area, attracting many more molecules, and increasing the growth to the degree that is more advanced, until the PCM is stable and there is no more crystal formation and ice is formed. The quick freezing process forms mainly small ice crystals, whereas the refrigeration in a long time forms a few big ice crystals. The long run gives time for the molecules of water to migrate towards 


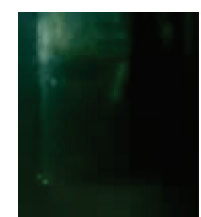

Liquid water
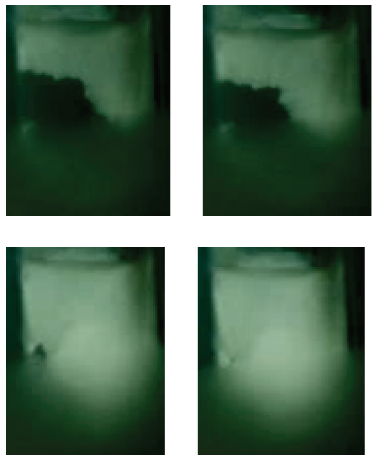

(a)
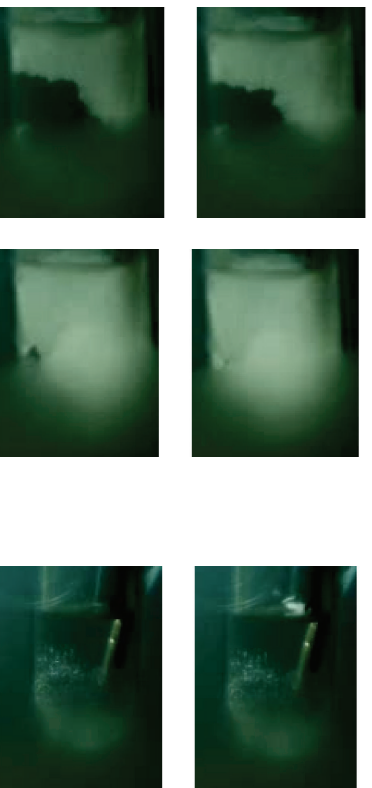

Liquid water
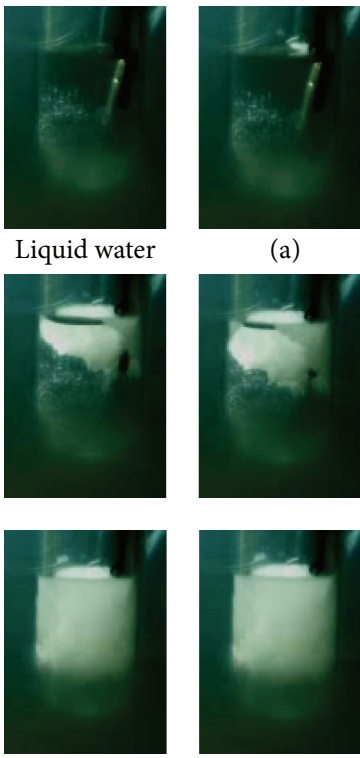

(a)
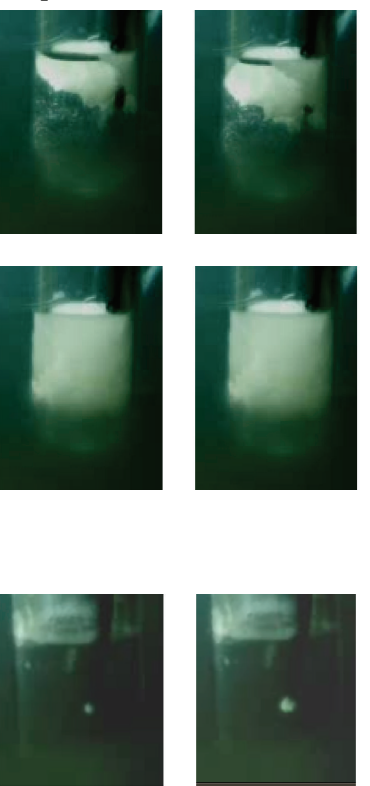

(a)

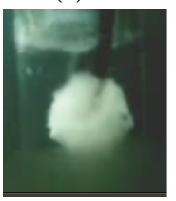

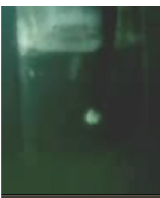

(b)

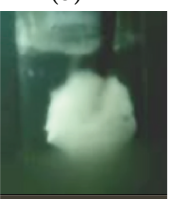

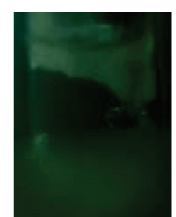

(b)
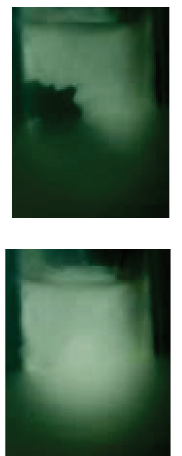

$12.5 \%$ soya oil ester

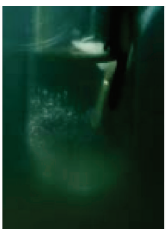

(b)
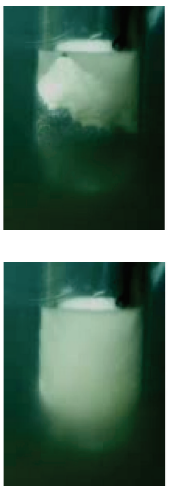

$15 \%$ soya oil ester

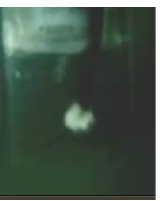

(c)

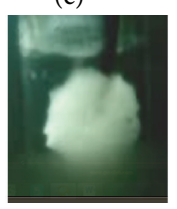

$17.5 \%$ soya oil ester

(c)
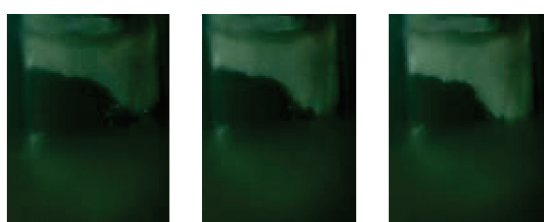

(c)
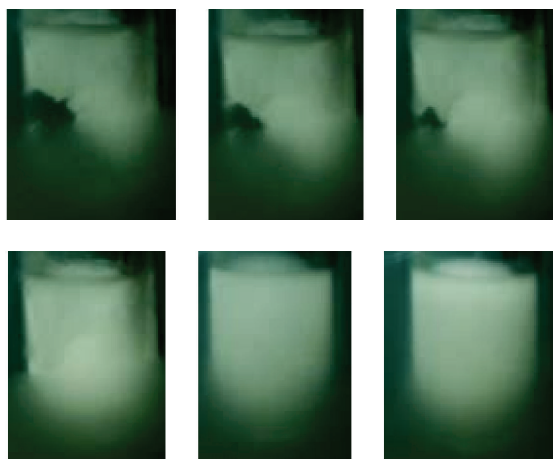

(d)
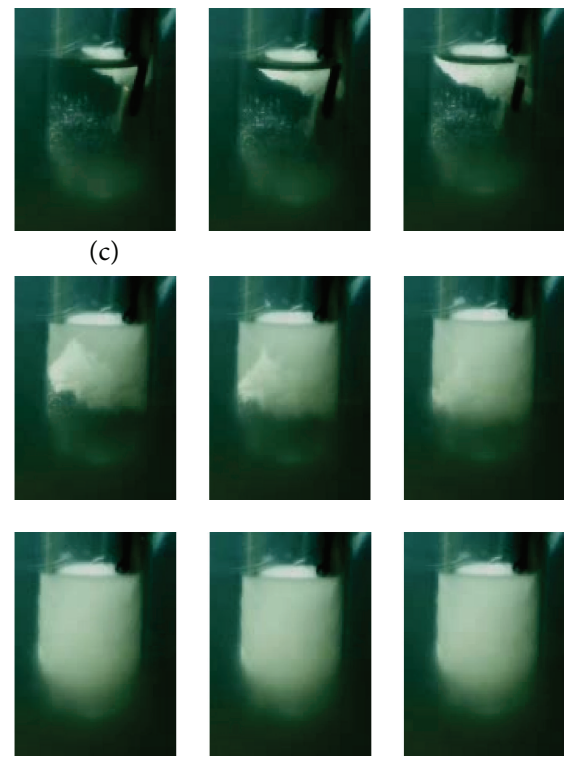

(d)
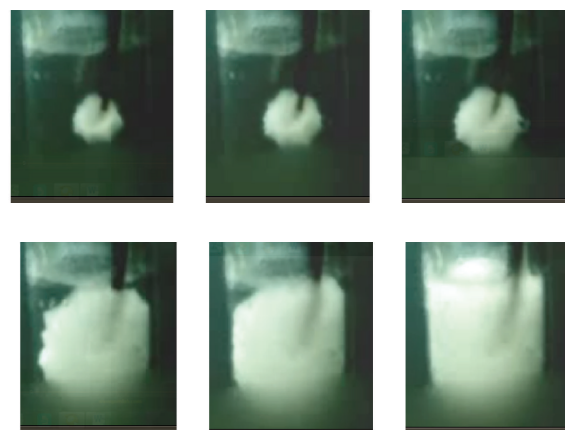

(d)

FIGURE 6: Cooling process of $12.5 \%, 15 \%$, and $17.5 \%$ of soya oil ester solutions in tap water. (a) Ice nuclei. (b) Growth ice crystal. (c) Initial formation of solid ice layer. (d) Complete formation of solid ice layer. ((c)-(d)) Ice crystal growth during freezing process. 
the nuclei that will be united with them to aggregate ice crystals so that there will be big ice crystals produced. It explains why water needs a long time to be frozen during the refrigeration.

The potential of ice nucleation of the PCM is indeed varied and depends on soya oil concentration. The formation of ice nucleation is quicker as the number of the solution's concentrations is increased. Supercooling degree is smaller at larger number of the solution's concentrations. The freezing point drops because the solution hardly releases the heat as a result of the attractive energy between fusing particle and fused substance. But the latent heat of the solution is slightly lower as the concentration of the solution increases because of the percentage of the water content in the solution reduced, as shown by lying line in T-history (Figure 5).

As shown in Figure 4, the freezing is faster and the supercooling degree is lower in tap water than in mineral water. As presented in Table 2, the impurity in tap water is higher. This shows that the impurity works as nucleating agent that reduces the supercooling and accelerates water freezing. The soya oil ester has hydrophilic head that attracts water and hydrophobic tail that repels water. Therefore, the addition of small number of soya oil esters in water makes agglomerations of groups of soya oil molecules. The mass of one conglomeration of oil molecules is much higher than that of the water molecules. As a result, the heat exchange increases largely so that the water freezes more quickly. The addition of soya oil reduces slightly the latent heat capacity due to lower latent heat capacity of soya oil. In other words, the quick freezing of water is mainly due to increasing of the heat exchange due to agglomerations of soya oil molecules in water.

Every different application needs different temperature of PCM. The PCM that has adjustable temperature is highly required. PCM needs to possess high level of latent heat. Thus, the least mixture containing the percentage of soya oil ester in water has the highest latent heat so that it can absorb, save, and release heat in a large quantity.

\section{Conclusions}

The process of ice frozen in the system of latent heat thermal energy storage (LHTES) needs the seeds of crystal to form ice. The role of heterogeneous ice nucleators is very effective in encouraging the ice nucleation in solution. The significant advancement which can be made in solving the big problems regarding the relative importance of agent nucleation of extrinsic ice for the supercooling can be analyzed. This method can be developed to set up ice nucleation, in limiting the supercooling according to the freezing temperature, either sensitive or cold. In this study, the additions of $12.5 \%$, $15 \%$, and $17.5 \%$ of soya oil ester in water solutions as PCM candidates can decrease tap water freezing point to $-6^{\circ} \mathrm{C}$, $-8^{\circ} \mathrm{C}$, and $-9.5^{\circ} \mathrm{C}$, respectively. A small amount of soya oil ester (agent of nucleation) solution in water becomes a very good candidate for PCM, since its characteristic is very similar to thermophysics of water. Sensitive freezing point and cooling that could be adjusted indicate that water-based soya oil solutions are suitable for low temperature cool storage application.

\section{Competing Interests}

The authors declare that they have no competing interests.

\section{Acknowledgments}

The authors acknowledge the financial support received from the Directorate General of Higher Education of the Ministry of Education and Culture of the Republic of Indonesia.

\section{References}

[1] A. Sharma, A. Shukla, C. R. Chen, and T.-N. Wu, "Development of phase change materials (PCMs) for low temperature energy storage applications," Sustainable Energy Technologies and Assessments, vol. 7, pp. 17-21, 2014.

[2] Y. Xia and X.-S. Zhang, "Experimental research on a doublelayer radiant floor system with phase change material under heating mode," Applied Thermal Engineering, vol. 96, pp. 600606, 2016.

[3] G. R. Dheep and A. Sreekumar, "Influence of accelerated thermal charging and discharging cycles on thermo-physical properties of organic phase change materials for solar thermal energy storage applications," Energy Conversion and Management, vol. 105, article 7371, pp. 13-19, 2015.

[4] P. Zhang, X. Xiao, and Z. W. Ma, "A review of the composite phase change materials: fabrication, characterization, mathematical modeling and application to performance enhancement," Applied Energy, vol. 165, pp. 472-510, 2016.

[5] W. E. O'Connor, R. Warzoha, R. Weigand, A. S. Fleischer, and A. P. Wemhoff, "Thermal property prediction and measurement of organic phase change materials in the liquid phase near the melting point," Applied Energy, vol. 132, pp. 496-506, 2014.

[6] X. Sun, Q. Zhang, M. A. Medina, and K. O. Lee, "Experimental observations on the heat transfer enhancement caused by natural convection during melting of solid-liquid phase change materials (PCMs)," Applied Energy, vol. 162, pp. 1453-1461, 2016.

[7] D. Yang, S. Shi, L. Xiong et al., "Paraffin/Palygorskite composite phase change materials for thermal energy storage," Solar Energy Materials \& Solar Cells, vol. 144, pp. 228-234, 2016.

[8] ASHRAE Inc, HVAC Applications Handbook, ASHRAE Inc, Atlanta, Ga, USA, 2007.

[9] M. F. Demirbas, "Thermal energy storage and phase change materials: an overview," Energy Sources Part B: Economics, Planning and Policy, vol. 1, no. 1, pp. 85-95, 2006.

[10] S. Mo, Y. Chen, L. Jia, and X. Luo, "Investigation on crystallization of $\mathrm{TiO}_{2}$-water nanofluids and deionized water," Applied Energy, vol. 93, pp. 65-70, 2012.

[11] S. L. Braga and J. J. Milón, "Visualization of dendritic ice growth in supercooled water inside cylindrical capsules," International Journal of Heat and Mass Transfer, vol. 55, no. 13-14, pp. 36943703, 2012.

[12] A. C. Marques, G. F. Davies, G. G. Maidment, J. A. Evans, and I. D. Wood, "Novel design and performance enhancement of domestic refrigerators with thermal storage," Applied Thermal Engineering, vol. 63, no. 2, pp. 511-519, 2014. 
[13] K. Nitsch, "Thermal analysis study on water freezing and supercooling," Journal of Thermal Analysis and Calorimetry, vol. 95, no. 1, pp. 11-14, 2009.

[14] Y. Zhang, M. Wang, X. Lin, and W. Huang, "Effect of substrate surface microstructure on heterogeneous nucleation behavior," Journal of Materials Science and Technology, vol. 28, no. 1, pp. 67-72, 2012.

[15] Z. Kazemi and S. M. Mortazavi, "A new method of application of hydrated salts on textiles to achieve thermoregulating properties," Thermochimica Acta, vol. 589, pp. 56-62, 2014.

[16] G. Li, Y. Hwang, and R. Radermacher, "Review of cold storage materials for air conditioning application," International Journal of Refrigeration, vol. 35, no. 8, pp. 2053-2077, 2012.

[17] W. Lu and S. A. Tassou, "Characterization and experimental investigation of phase change materials for chilled food refrigerated cabinet applications," Applied Energy, vol. 112, pp. 13761382, 2013.

[18] H. Mehling and L. F. Cabeza, Heat and Cold Storage with PCM, Springer, New York, NY, USA, 2008.

[19] Freezing Point Depression, http://en.wikipedia.org/wiki/Freezingpoint-depression.

[20] R. A. Taylor, N. Tsafnat, and A. Washer, "Experimental characterisation of sub-cooling in hydrated salt phase change materials," Applied Thermal Engineering, vol. 93, pp. 935-938, 2016.

[21] L. F. Cabeza, F. Badia, J. Illa, and J. Roca, "Corrosion experiments on salt hydrates used as phase change materials in cold storage," Applied Thermal Engineering, vol. 30, pp. 2652-2657, 2001.

[22] R. K. Sharma, P. Ganesan, V. V. Tyagi, H. S. C. Metselaar, and S. C. Sandaran, "Developments in organic solid-liquid phase change materials and their applications in thermal energy storage," Energy Conversion and Management, vol. 95, pp. 193228, 2015.

[23] L. C. Liston, Y. Farnam, M. Krafcik, J. Weiss, K. Erk, and B. Y. Tao, "Binary mixtures of fatty acid methyl esters as phase change materials for low temperature applications," Applied Thermal Engineering, vol. 96, pp. 501-507, 2016.

[24] I. M. Rasta, I. N. G. Wardana, N. Hamidi, and M. N. Sasongko, "The role of heterogeneous nucleation in water based phase change material for medium temperature refrigeration," $A R P N$ Journal of Engineering and Applied Sciences, vol. 11, no. 2, pp. 978-985, 2016.

[25] S. Wi, J. Seo, S.-G. Jeong, S. J. Chang, Y. Kang, and S. Kim, "Thermal properties of shape-stabilized phase change materials using fatty acid ester and exfoliated graphite nanoplatelets for saving energy in buildings," Solar Energy Materials \& Solar Cells, vol. 143, pp. 168-173, 2015.

[26] H. Fauzi, H. S. C. Metselaar, T. M. I. Mahlia, M. Silakhori, and H. C. Ong, "Thermal characteristic reliability of fatty acid binary mixtures as phase change materials (PCMs) for thermal energy storage applications," Applied Thermal Engineering, vol. 80, pp. 127-131, 2015.

[27] K. Cellat, B. Beyhan, C. Güngör et al., “Thermal enhancement of concrete by adding bio-based fatty acids as phase change materials," Energy and Buildings, vol. 106, pp. 156-163, 2015.

[28] S.-G. Jeong, O. Chung, S. Yu, S. Kim, and S. Kim, "Improvement of the thermal properties of Bio-based PCM using exfoliated graphite nanoplatelets," Solar Energy Materials and Solar Cells, vol. 117, pp. 87-92, 2013.
[29] H.-Y. Wang and S.-S. Lu, "Study on thermal properties of phase change material by an optical DSC system," Applied Thermal Engineering, vol. 60, no. 1-2, pp. 132-136, 2013.

[30] J. Lei, J. Yang, and E.-H. Yang, "Energy performance of building envelopes integrated with phase change materials for cooling load reduction in tropical Singapore," Applied Energy, vol. 162, pp. 207-217, 2016.

[31] M. E. Sahagian and H. D. Goff, "Fundamentals aspects of freezing process," in Freezing Effects on Food Quality, L. E. Jeremiah, Ed., pp. 1-50, Marcel Dekker, New York, NY, USA, 1996.

[32] J. P. Fellows, Food Processing Technology Principles and Practice, Woodhead, Cambridge, UK, 2nd edition, 2000.

[33] B. J. Murray, S. L. Broadley, T. W. Wilson et al., "Kinetics of the homogeneous freezing of water," Physical Chemistry Chemical Physics, vol. 12, no. 35, pp. 10380-10387, 2010.

[34] H. Mehling, L. F. Cabeza, and M. Yamaha, "Phase change materials: application fundamentals," in Thermal Energy Storage for Sustainable Energy Consumption, H. Ö. Pakso, Ed., Springer, Berlin, Germany, 2007. 

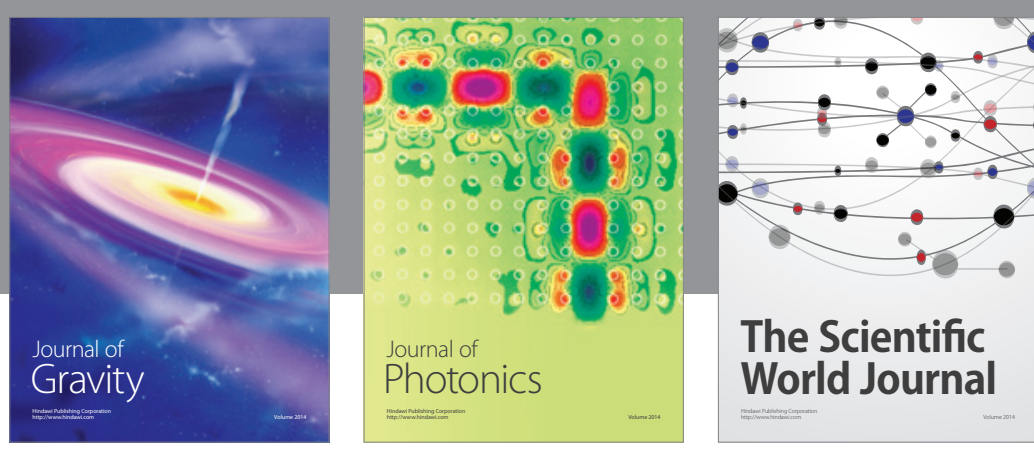

The Scientific World Journal
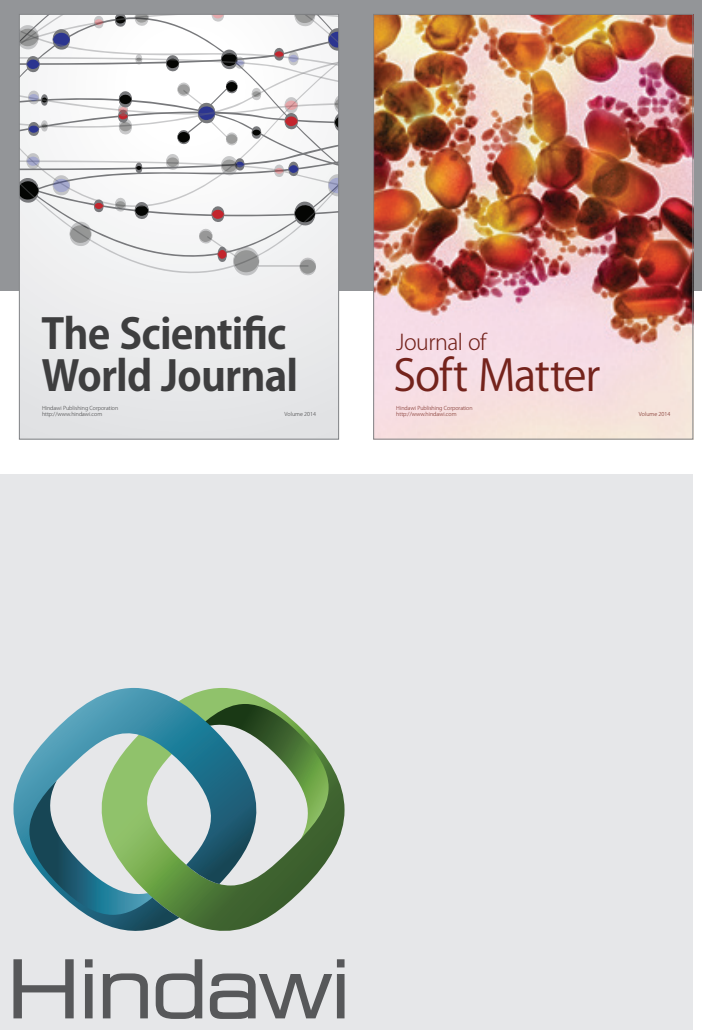

Submit your manuscripts at

http://www.hindawi.com

nternational Journal of

Statistical Mechanics
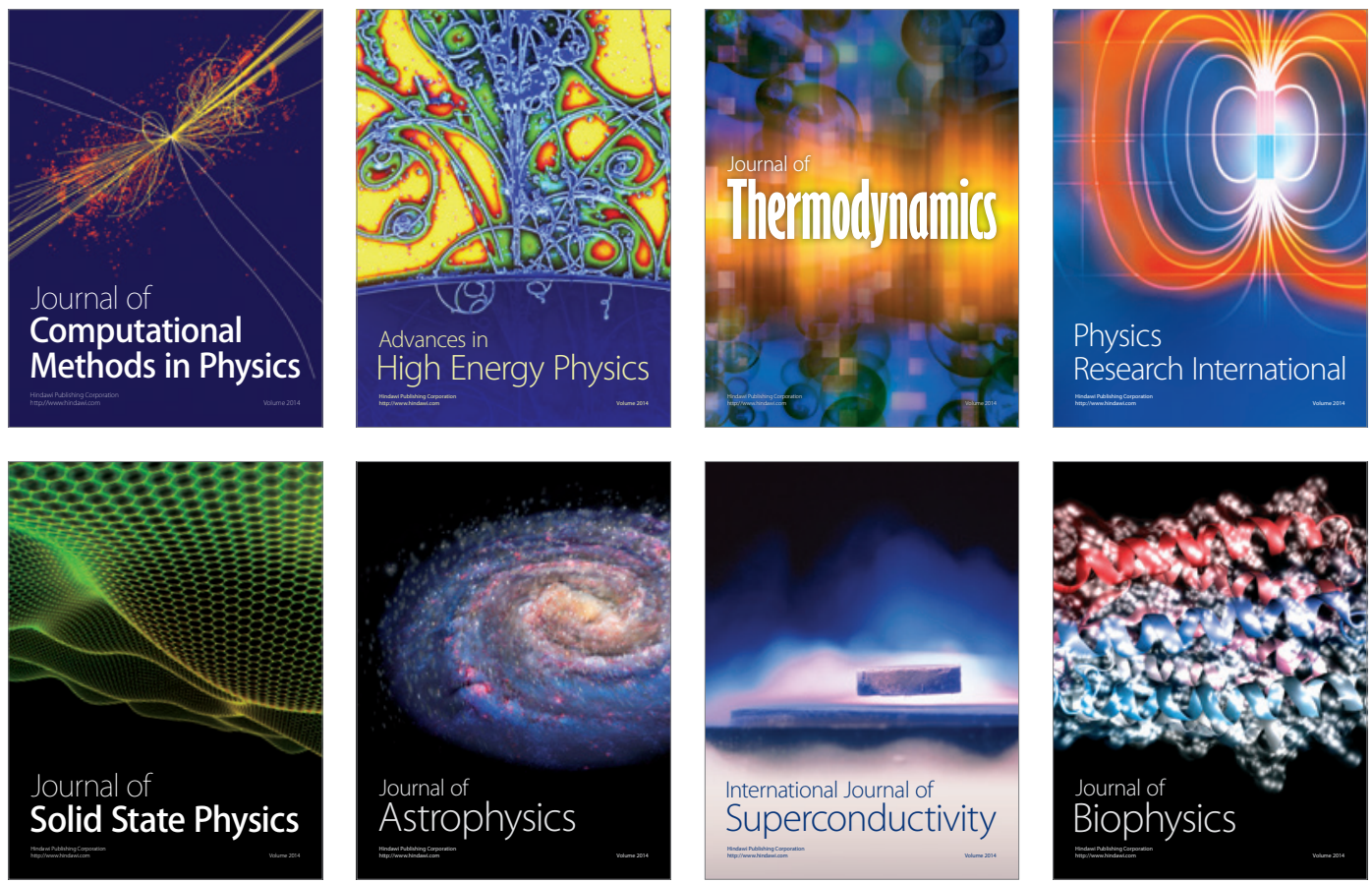
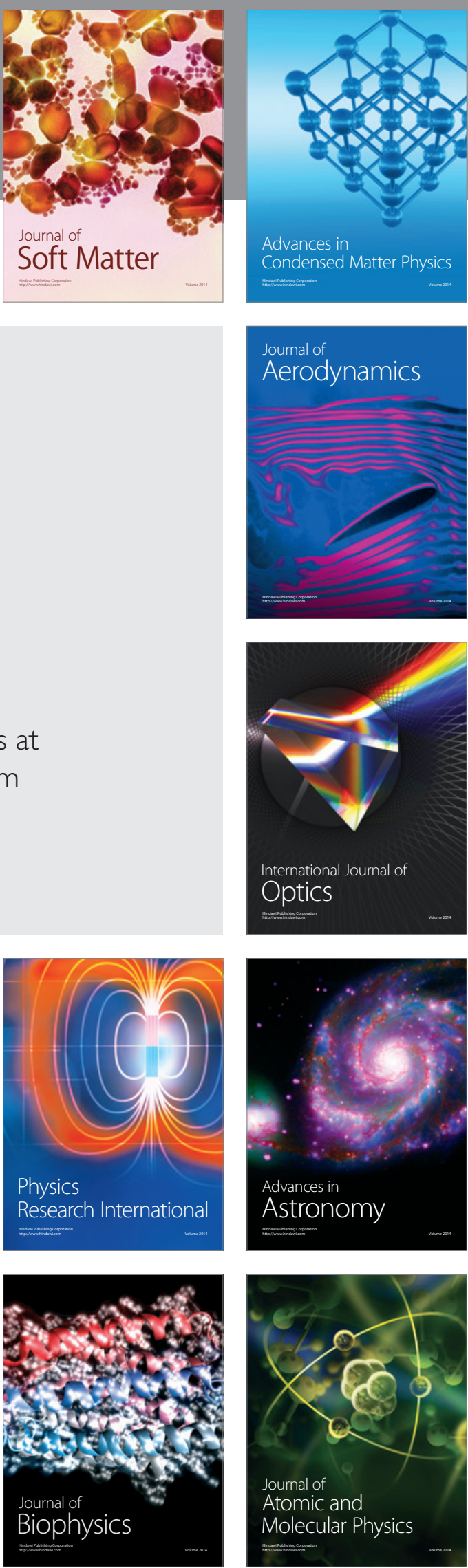